\title{
My Appreciation of Enric Trillas: A Personal Note
}

\author{
Ramon Lopez de Mantaras
}

I met Professor Trillas in 1976 when he visited the Laboratory for Analysis and Architecture of Systems (LAAS) from the CNRS in Toulouse (France). At that time I was pursuing my PhD in Automatic Control at that lab under the supervision of Prof. Josep Aguilar-Martin. His visit to the LAAS was just a couple of years after he had become interested in the field of Fuzzy Sets. Coincidentally, the same year Professor Zadeh also visited the LAAS and I also had the privilege to meet him personally. Meeting these two outstanding personalities the same year changed my life. Indeed, in 1977, after completing my PhD I had the chance to go to Berkeley to study Fuzzy Systems and Artificial Intelligence under the supervision of Professor Zadeh and, after returning to Spain, in September 1980 Professor Trillas offered me a teaching assistant position at the Technical University of Catalonia (UPC) where, under his supervision, I completed a $\mathrm{PhD}$ in Computer Science with a dissertation on Machine Learning for Pattern Classification. After my PhD I became Assistant and then Associate Professor at the UPC collaborating with Professor Trillas and actively participating in the weekly seminars on Fuzzy Logic that he was leading at the Mathematics department. During those years, he was also the main promoter of a series of Fall Seminars on Applied Logic taking place at the beautiful island of Mallorca during the mid eighties. I have very happy memories of this series of seminars where the, then very small, Spanish Fuzzy Logic community would gather with many of our European colleagues. Nowadays, thanks to the pioneering efforts of Professor Trillas, the Spanish Fuzzy community has grown both in quantity and in quality becoming one of the top fuzzy communities in the world.

In 1984, Professor Trillas was appointed President of the Spanish National Research Council (CSIC), and in early 1985 he asked me to initiate an AI department at the newly established Centre of Advanced Studies located in Blanes, a village on the Mediterranean coast about $70 \mathrm{Km}$ north of Barcelona. We started AI research activities at this Centre in October 1985, with the collaboration of Dr. Jaume Agust, from the Autonomous University of Barcelona, Prof. Josep Aguilar-Martin, my former PhD advisor from the CNRS in Toulouse, and Professor Settimo Termini, from the CNR in Naples. The group grew fast and in 1994 we became the Artificial Intelligence Research Institute (IIIA) and moved to a new building located in the campus of 
the Autonomous University of Barcelona. The IIIA is now one of the leading AI research centers in Europe. Since then, well over 2000 papers have been published by IIIA members, over $80 \mathrm{PhDs}$ have been completed, and over 100 research projects - including 24 European projects - and contracts with industry have been done. The total funding of these projects exceeds 20 million Euros, accounting for $40 \%$ of the total IIIA budget for all this period. IIIA researchers have received over 40 international awards and recognitions, including 15 best paper awards at international conferences, 6 outstanding $\mathrm{PhD}$ thesis awards, the 2012 "EUSFLAT Best PhD Dissertation" award, the 2011 "IFAAMAS Victor Lesser Distinguished Dissertation" award, and the 2011 "AAAI Robert S. Engelmore". In addition, many IIIA senior members are, or have been, members of the editorial boards of more than 30 international journals, have participated in hundreds of program committees, and are on the board of several governing bodies of international AI organizations such as IJCAI, IFAAMAS, ACP and EUSFLAT.

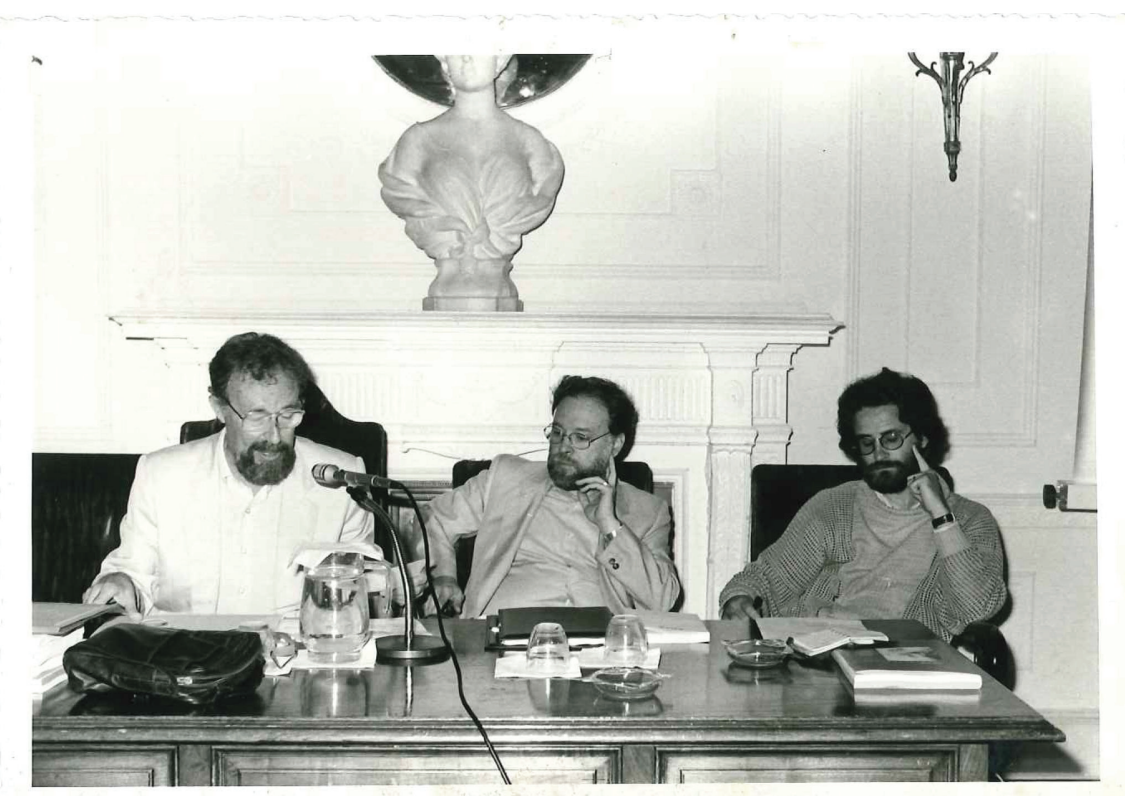

Fig. 10.1. UIMP Santander, 1985 (from left) Carlos Angulo, Enric Trillas, Ramon Lopez de Mantaras.

At present, the research activities at the IIIA are structured around three departments: Learning Systems, Multi-agent Systems, and Logic, Reasoning \& Search. This last department always has been and still is very active in the area of Fuzzy logic and Fuzzy systems. 


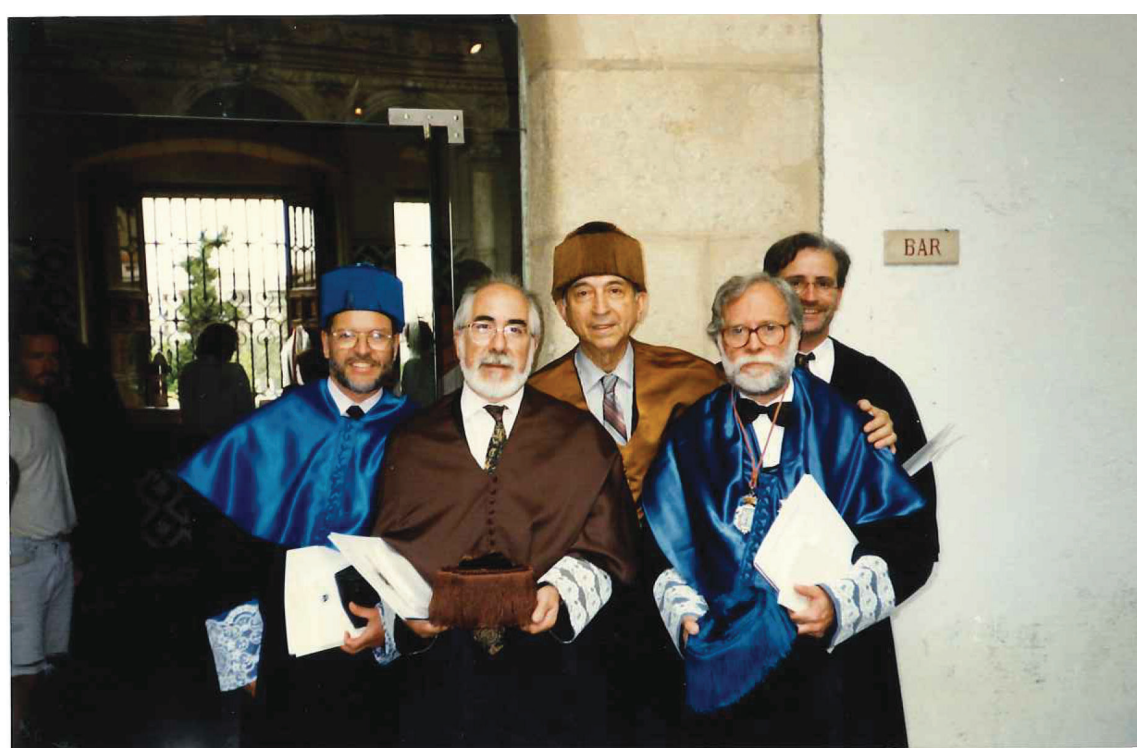

Fig. 10.2. Honoris Causa Doctorate of Lotfi A. Zadeh at the University of Granada: (from left) Francesc Esteva, Joan Jacas, Lotfi, Enric and myself.

Our research has been and is always guided by concrete and challenging applications in fields such as health, e-commerce, automated negotiation, conflict resolution, music, tourism, logistics, supply chain management, transport, energy, data privacy, and social networks, among others. Several of our systems, tools and applications have been distributed outside the institute and in some cases have been commercialized. Among the many AI applications developed, the most recent ones are: Prediction of energy demand in intelligent buildings; early detection of potential failures in windmill turbines for electrical power generation; improving the customers shopping experience in supermarkets; managing safe personalized tourism for disabled persons; AI tools for social networks-based music education; on-line digital games that are worth playing by older people for active and positive aging; social networking using autonomic software agents to enrich, encourage, and enliven online cultural experiences in virtual visits to museums; recruitment intelligent matching system to improve online job searching; and automatic generation of audiovisual narrative such as summaries of soccer matches or other types of TV events.

The existence of the Technological Development Unit (UDT) provides technological support to our research activities and improves our technology transfer capabilities by channeling contacts with industry. In particular, we keep strong ties with our three spin-off companies: iSOCO (http://www.isoco.com), STRANDS (http://strands.com), and COGNICOR (http://cognicor.com). 


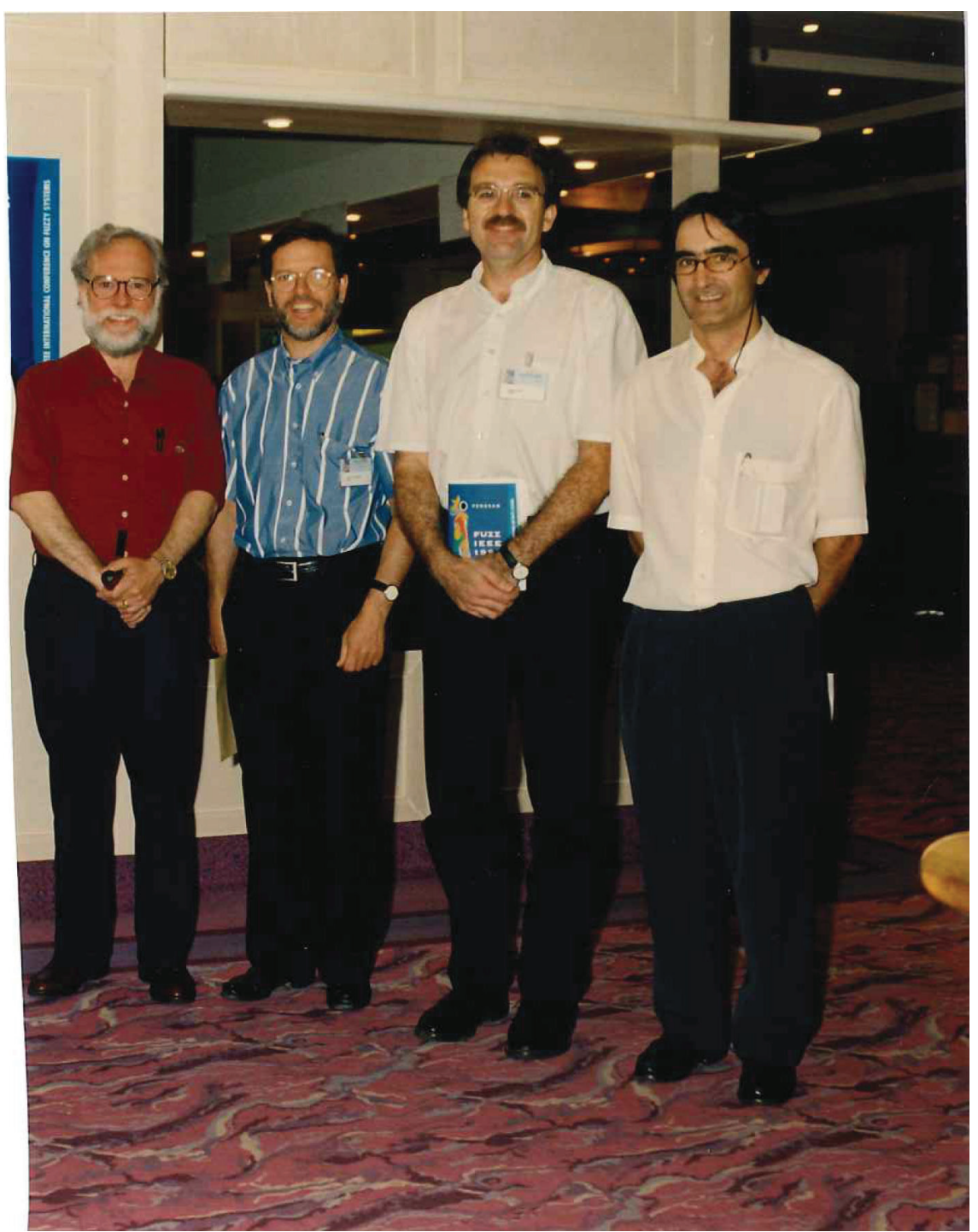

Fig. 10.3. FUZZ-IEEE 1997, Barcelona: Enric, Francesc, Lluis Godo and Pere Garcia. 
Our first spin-off, ISOCO, was set up in 1999 dedicated to the design of intelligent software components for Internet-related applications. Today, ISOCO is a leading company within its sector in Spain. STRANDS, was started in 2004 dedicated to recommendation Systems particularly in the finances sector that nowadays is also a leading company in Spain. COGNICOR was founded in 2011 based on the results of a large, over five million Euros, project called Agreement Technologies. This company develops software products for the automatic resolution of customers complaints using machine learning and case-based reasoning techniques. COGNICOR has received several awards, including the prestigious "2012 European Union Tech All Stars Competition".

I believe that, thanks to the vision and support of Enric Trillas, the IIIA has played and is playing a major role in several areas of AI and particularly in the mathematical foundations and applications of Fuzzy Logic and Fuzzy AI Systems.

\section{Acknowledgment}

It has been, and still is, a great honor to enjoy such a long-standing friendship with Professor Trillas. He has undoubtedly had a very strong influence in my life because he has always been a model of what is to be an excellent person and an outstanding scientist as well as how to promote research teams with high human qualities. I would probably (or possibly?) not be a scientist and the very successful IIIA research lab would certainly not exist if I had not met him in 1976. This paper is in homage to him, to his friendship, to his wisdom and his vision. 